\title{
HUMANIORA DI ERA GLOBALISASI, MASIHKAH RELEVAN?
}

\author{
Wawan Darmawan, Murdiyah Winarti \\ Email : wawand@upi.edu \\ Universitas Pendidikan Indonesia
}

\begin{abstract}
Abstrak
Memasuki era globalisasi masyarakat Indonesia di hadapkan pada berbagai persoalan. Globalisasi telah menempatkan ilmu sains-keteknikan sebagai ilmu yang mengedepankan kemampuan intelektual manusia yang melahirkan invensi dan inovasi sesuai dengan "kebutuhan masyarakat" daripada humaniora yang mempunyai kecenderungan untuk "memanusiakan" manusia. Keadaan ini terlihat di beberapa negara maju baik Eropa, Amerika dan Asia (Jepang) yang kecenderungannya mengutamakan sains teknologi. Isu, meminimalisir, sampai menghapuskan beberapa ilmu humaniora di beberapa universitas terjadi di beberapa negara memungkinkan masuk pada negara berkembang, termasuk Indonesia. Humaniora, dapatkah bertahan dalam arus globalisasi?
\end{abstract}

Kata Kunci: humaniora, sejarah, globalisasI, relevan

\section{Pendahuluan}

Menurut Wallerstein sebagaimana dikutip oleh Gardner (2000:528), globalisasi telah menempatkan sebagian besar masyarakat Indonesia, bersama dengan negara-negara berkembang lainnya di Afrika, ke dalam posisi periphery. Negara-negara industri baru seperti Korea, Taiwan, Singapura dan Brazil sebagai semi-periphery. Sementara itu negara-negara di Eropa, Amerika, dan Jepang (di Asia) menjadi negara-negara inti yang miskin dari segi sumber daya alam tapi kuat dari segi sumber daya manusia telah mampu menghadapi era globalisasi. Derasnya arus globalisasi dan kuatnya kebutuhan manusia secara fisik, beberapa negara inti mulai mengendorkan peran humaniora dalam kehidupan masyarakat.

Globalisasi telah menjadi salah satu topik yang banyak diperdebatkan sejak awal 1990-an, terutama di kalangan sarjana humaniora dan ilmu sosial. Hal yang menjadi bahan perdebatan karena semakin banyak orang menyadari bahwa mereka tidak dapat bertahan tanpa globalisasi. Di Cina, misalnya, di antara orang-orang muda di sana, terjadi apa yang disebut dengan 'penyakit telepon seluler' yang dapat diamati di mana-mana: anak-anak ini hampir tidak mampu melakukan apa pun jika mereka kehilangan ponsel mereka. Dalam menulis karya tulis, mahasiswa lebih suka mengunduh referensi dari situs web daripada meminjam buku atau jurnal akademis dari 
perpustakaan. Banyak dari mereka lebih suka membaca online daripada membaca hard copy dari materi referensi. Orang-orang mungkin akan mengajukan pertanyaan-pertanyaan: "Apa gunanya mempelajari humaniora? Dan apakah humaniora akan membawa peluang untuk persaingan pekerjaan di era globalisasi? Jika jawaban atas pertanyaan-pertanyaan ini negatif, mengapa kemudian kita harus tetap mempertahankan mata kuliah humaniora di universitas kita?

Pertanyaan yang terjadi di Cina tahun 1990-an terjawab di Jepang. Hal itu sebagaimana ditulis oleh Fadly Rahman dengan judul "Senjakala Humaniora" yang dimuat Harian Kompas (2016). Tulisan ini memperlihatkan bagaimana Pemerintah Jepang yang telah membuat kebijakan dengan memerintahkan universitas-universitas di sana menutup fakultas-fakultas ilmu sosial. Penutupan itu tiada lain dikarenakan Jepang lebih mengedepankan pendidikan kejuruan untuk mengantisipasi "kebutuhan-kebutuhan masyarakat" sesuai kebutuhan arus globalisasi. Modernitas dengan segala kecanggihan, kecepatan, dan keinstanan teknologi telah memposisikan humaniora "perlahan-lahan" terpinggirkan. Kebutuhan ekonomi dan industri pasar yang mengatasnamakan "kebutuhan masyarakat" seolah menjadi skala prioritas daripada humaniora.

Jika gejala meminimalisasi atau mungkin menghilangkan humaniora tersebut masuk ke Indonesia, karena ciri-ciri globalisasi sudah memasuki kehidupan masyarakat Indonesia, nilainilai humaniora yang dapat membentuk karakter moral masyarakat Indonesia lama-lama akan hilang. Dengan begitu, sikap jujur, adil, rasa empati, toleran, tanggung jawab dan kesadaran dalam menjaga keharmonisan hidup manusia dengan manusia lainnya akan luntur dalam jiwanya. Menurut Alhumami (2016) “Jangankan jika terhapus atau dihapus, humaniora yang masih tumbuh subur di perguruan tinggi Indonesia dengan komposisi 57\% ilmu-ilmu sosialhumaniora lebih besar dari ilmu sains-keteknikan yang hanya 43\%, nilai-nilai kemanusiaan bangsa ini pada kenyataannya sudah mulai luntur".

Kita dapat lihat bagaimana pertumbuhan nilai-nilai kemanusian atau karakter bangsa Indonesia di era globalisasi sekarang ini. Berdasarkan kebijakan pendidikan yang diberlakukan oleh Pemerintah Indonesia, lembaga pendidikan yang ada harus mengembangkan "pendidikan karakter dan revolusi mental". Hal itu disebabkan krisis moral yang menimpa mental bangsa Indonesia sudah mengkhawatirkan. Persoalan krisis moral (krisis kemanusiaan) itu antara lain peredaran narkoba, kekerasan, pencurian, perampokan, kejahatan seksual (lihat kasus terbaru terhadap prostitusi online), perkelahian massa (antar para pelajar, pemuda antara kampung/desa, 
masyarakat antar suku), kehidupan ekonomi yang konsumtif, dan kehidupan politik yang tidak produktif. Persoalan lain yang seolah tidak pernah habis dalam pemberitaan adalah korupsi. Korupsi yang melibatkan misal para pejabat, mulai dari tingkat desa sampai bupati, walikota dan gubernur, anggota dewan (DPR dan DPRD), mantan menteri beserta jajarannya. Status mereka sudah masuk tersangka dan terpidana. Untuk itu, kondisi bangsa Indonesia yang memprihatinkan dalam kehidupan sekarang memerlukan generasi yang punya sense of humanities yang dapat memutus generasi yang krisis rasa kemanusiaan tersebut (Rahman, 2016).

Yang menjadi masalah "Mengapa muncul gagasan untuk menutup atau membatasi fakultas-fakultas humaniora?" Apakah di era arus globalisasi, pendidikan humaniora dianggap tidak relevan? Permasalahan-permasalahan ini tampaknya menarik untuk dikaji kembali.

\section{Metode}

Untuk membahas ataupun mengkaji permasalah-permasalahan yang dikemukan di atas, penulis menggunakan pendekatan Erklaren antar factor dengan mencari hubungan pengaruh atau sebab-akibat/kausalitas antara kemajuan modernitas dalam arus globalisasi dengan perkembangan humaniora. Di sini akan dikaji apakah modernitas yang disesuaikan dengan kebutuhan pragmatis masyarakat telah menyebabkan kebutuhan nilai-nilai kemanusiaan dalam humaniora menjadi tidak dibutuhkan lagi? Atau sebaliknya, apakah perkembangan humaniora tidak dapat mengimbangi laju pertumbuhan modernitas dalam arus globalisasi? Pendekatan lainnya Verstehen dengan melihat situasi atau kondisi tertentu, khususnya mengapa Jepang dan beberapa Negara lain di Negara-negara maju mencoba menghapus humaniora. Selanjutnya secara verstehen juga akan dilihat bagaimana situasi dan kondisi di Indonesia jika hal itu diberlakukan.

\section{Pembahasan}

\section{Konsep Humaniora}

Pengetahuan manusia umumnya dapat diklasifikasi atas tiga kelompok besar, yaitu: pertama, ilmu-ilmu alamiah (natural sciences); kedua ilmu-ilmu sosial (social sciences); dan ketiga ilmu-ilmu kemanusiaan (humanaties) atau dikenal juga dengan sebutan humaniora (Kartodirdjo, 1992:126). Sementara itu Dilthey membagi ilmu menjadi dua, yaitu ilmu tentang 
dunia luar atau Naturwissenschaften (ilmu-ilmu alam) dan ilmu tentang dunia dalam atau Geisteswissenchaften (ilmu-ilmu kemanusiaan) (Rochiaty, 2015:69). Menurut Sjamsuddin (2012:227)., tanpa mempertentangkan humaniora dalam hubungan metodologis dapat masuk ke dalam ilmu-ilmu sosial

Ilmu-ilmu kemanusiaan ini mempelajari manifestasi-manifestasi kehadiaran (eksistensi) kejiwaan (spiritual) manusia. Belum ada pengertian baku apa itu humaniora, namun dengan mengaju pada pendapat Ralph Barton Perry yang mengutip Webster's New International Dictionary menyebutkan bahwa humanities atau ilmu-ilmu kemanusiaan itu adalah cabangcabang dari pengetahuan "santun" (polite learning) seperti bahasa-bahasa Yunani dan Latin (Klasik kuno), sastra (belles-lettres), bahkan pengetahuan sekuler sebagai lawan dari pengetahuan teologi. Begitu pula kutipannya dari kamus Education and Instruction menyebutkan bahwa ilmu-ilmu kemanusiaan itu terdiri dari cabang kajian tertentu yang mempunyai kecenderungan untuk "memanusiakan" (humanize) manusia sebagai lawan dari ilmu-ilmu fisika yang berkecenderungan untuk mengembangkan kemampuan-kemampuan intelektual manusia. Kamus yang sama juga menyebutkan bahwa ilmu-ilmu kemanusiaan itu termasuk ke dalam "pendidikan liberal" (liberal education) sebagai lawan dari "pendidikan praktis" (practical educaion) (Sjamsuddin, 2012:216).

Pada dasarnya ilmu-ilmu kemanusiaan mempelajari sejarah dari apa yang telah dibuat, atau dipikirkan, atau diharapkan, atau bahkan kegagalan manusia melalui penelitian objek-objek yang dibentuk oleh pengalaman dan imajinasi manusia. Pokok-pokok kajian humaniora ialah filsafat, interpretasi tentang sastra dan sejarah, kritik tentang seni, musik, dan teater yang semuanya membahas tentang batas-batas, kedalaman-kedalaman, dan kapasitas-kapasitas dari semangat manusia (Grumet, 1985: 135). Untuk itu tidak mengherankan jika arti penting humaniora ini diperlukan bagi pendidikan umum untuk mengembangkan pribadi seseorang agar tumbuh harmonis dan seimbang. Hal itu sebagaimana dijelaskan Sjamsuddin (2012: 217-218), bahwa humaniora menekankan kepada: 1) Keunikan manusia sendiri, melalui intelegensinya, mampu mengontrol perkembangan fisik dan mental; juga menjawab pertanyaan-pertanyaan dasar tentang eksistensi, menemukan pola-pola dari kehidupan, menikmati suatu pelepasan kreatif dari emosi-emosi; dan 2) Pencarian manusia akan nilai-nilai (values). 
Dalam pencarian keunikan manusia itu sendiri dan pencarian manusia akan nilai-nilai, manusia menggunakan daya-daya kreatifnya. Salah satu nilai terpenting yang ditekankan oleh humaniora ialah individualitas. Konsep ini acapkali dibangun ke dalam struktur dari suatu program humaniora dan mengajarkan akan pentingnya perbedaan-perbedaan manusia di samping persamaan-persamaan. Konsekuensinya proyek-proyek kreatif acapkali membentuk suatu bagian yang penting dalam program-program ilmu-ilmu kemanusiaan.

\section{Humaniora dan Arus Globalisasi di Indonesia}

Rahman (2016) menginformasikan ada kabar tidak sedap yang datang dari Jepang, bahwa pada September 2015, Pemerintah Jepang memerintahkan universitas-universitas di sana menutup fakultas-fakultas ilmu sosial dan humaniora. Dari 60 universitas nasional, 26 diantaranya telah mengonfirmasi akan menutup atau menimbang kembali perintah pemerintah itu. Perintah yang merupakan bagian dari upaya Perdana Menteri Shinzo Abe itu dimaksudkan untuk mempromosikan lebih banyak pendidikan kejuruan "yang lebih baik" dalam mengantisipasi "kebutuhan-kebutuhan masyarakat". Patut disayangkan, kemajuan Jepang yang sejak akhir abad ke-19 dipupuk dengan nilai-nilai luhur filosofi, sejarah, dan budayanya perlahan-lahan kini terkikis ketika humaniora sebagai pengontrol laju modernitas telah dianggap malafungsi. Tampaknya di tengah arus kecanggihan, kecepatan, dan keinstanan teknologi, posisi humaniora perlahan-lahan terpinggirkan oleh kebutuhan ekonomi dan industri pasar yang mengatasnamakan "kebutuhan masyarakat".

Bukan hanya di Jepang, gejala menghapus humaniora sudah mengglobal sebagaimana diramalkan Terry Eagleton dalam tulisannya, The Death of Universities (2010). Menurut Eagleton, jika disiplin humaniora tersingkir dari universitas, maka tidak mungkin universitas bisa berdiri tanpanya. Dan, ketika ilmu sejarah, arkeologi, antropologi, filsafat, linguistik, sastra, dan seni menjadi tak lebih dari sekadar "artefak pengetahuan" belaka, maka jelas ini telah mengingkari landasan historis dan filosofis universitas itu sendiri yang sejak abad ke-18 tak bisa dipisahkan dari peran penting disiplin ilmu-ilmu kemanusiaan, humane disciplines. Lihat saja, ketika Revolusi Industri bergeliat pada abad ke-18, saat itu lembaga-lembaga universitas di Eropa justru mengembangkan humaniora modern sebagai disiplin untuk mengimbangi laju kapitalisme dan modernisme. Posisi dan fungsinya ini tidak lain untuk menjaga nilai-nilai dan ide-ide kemanusiaan demi mewujudkan harmonisasi kehidupan. Humaniora memiliki relasi 
sinergis dengan disiplin ilmu lainnya. Relasi itu menciptakan gagasan-gagasan humanistis. Sinergi antara humaniora dengan disiplin ilmu lainnya (khususnya sains-keteknikan) diharapkan dapat menjadi kontrol untuk mengarahkan berbagai aspek kehidupan menjadi lebih manusiawi. Untuk itu Eagleton (2010) menyampaikan juga tidak masuk akal jika humaniora akan mnghilang dari universitas. Ini seperti pertanyaan "apakah alkohol akan hilang dari pub, atau egoisme dari Hollywood. Sama seperti tidak mungkin ada pub tanpa alkohol, jadi tidak mungkin ada universitas tanpa humaniora".

Perguruan Tinggi memiliki dua peran pokok, yaitu (1) memberikan pelayanan pendidikan dan (2) mengembangkan ilmu pengetahuan dan teknologi melalui riset yang melahirkan invensi dan inovasi. Menurut Marwah Daud Ibrahim (Latif, 1994: 17) mengemukakan bahwa yang dimaksud dengan ilmu pengetahuan adalah suatu jawaban sistematis dari kata "mengapa" (know why), sedangkan teknologi adalah jawaban praktis dari pertanyaan "bagaimana" (know how). Kedua peran sentral ini berkaitan dengan keberhasilan pembangunan ekonomi, antara lain oleh penduduk berpendidikan tinggi, berpengetahuan, memiliki keterampilan dan kemahiran teknis, serta menguasai teknologi. Untuk itu, perguruan tinggi harus menghasilkan SDM yang berkualitas, yang menguasai bidang ilmu tertentu untuk mendukung pembangunan.

Kenyataan di lapangan, Kemenristekdikti mencatat program studi yang ada di Perguruan Tinggi Indonesia yang berjumlah 23.747 yang terbagi ke dalam dua kelompok: (1) sainsketeknikan, antara lain MIPA, teknik, kedokteran, kesehatan, dan pertanian sebanyak 43\%, dan (2) ilmu-ilmu sosial-humaniora, antara lain ekonomi, manajemen, politik, hukum, filsafat, sejarah, sosiologi, dan agama sebesar 57\% (Alhumami, 2016). Tidak mengherankan jika antara kebutuhan pasar dan lulusan sarjana yang dihasilkan tidak seimbang, karena yang dibutuhkan sains-keteknikan sementara lulusan banyak didominasi oleh bidang ilmu-ilmu sosial dan humaniora. Untuk mengatasi ketimpangan ini, tidak ada pilihan lain bagi pemerintah dan perguruan tinggi Indonesia melalui percepatan dalam menghasilkan sarjana-sarjana teknik. Artinya Pemerintah Indonesia kebijakan yang diambil berbeda dengan Negara lain yang telah mengurangi atau menghapus ilmu sosial-humaniora, tetapi memberi keseimbangan diantara keduanya.

Untuk kondisi Indonesia, spirit humaniora tetap menyala meskipun kebutuhan pangsa pasar banyak membutuhkan sarjana sains-teknologi. Ada juga wacana untuk mengubah porsi 
sains-keteknikan dengan sosial-humaniora yang seimbang. Menurut penulis, jika ditafsirkan dari perkembangan yang mungkin timbul kemudian/selanjutnya secara hermeneutika, tampaknya tidak ada masalah. Hal itu disebabkan perubahan proporsi program studi ini sama sekali tidak berarti akan ada superioritas suatu bidang ilmu atas ilmu lainnya. Kebijakan ini juga tidak mengindikasikan bahwa bidang ilmu sosial-humaniora merupakan subordinat bidang sainsketeknikan.

Globalisasi yang berdimensi sangat luas dengan kompleksitas masalah memerlukan peran semua ilmu, termasuk ilmu social. Sosial-humaniora bisa membuat analisis melalui penelitian empiris untuk memetakan masalah-masalah yang muncul di masyarakat dan menghimpun isu-isu strategis untuk perencanaan pembangunan. Ilmuan sosial-humaniora juga dapat membuat analisis mengenai dampak negative pembangunan masyarakat. Peran sentral ilmu sosialhumaniora ini menunjukkan jalan agar pembangunan dapat memberikan manfaat bagi masyarakat. Untuk itu tidak mungkin ilmu sosial-humaniora dapat digantikan oleh ilmu sainsketeknikan. Kedua-keduanya memiliki peran dan kontribusi yang sama dalam pembangunan sesuai kebutuhan masyarakat.

Peran penting sosial-humaniora dalam arus globalisasi yang lebih banyak memerlukan sains-keteknikan tetap ada. Hal ini sebagaimana diungkap oleh Nasikun (2004: 1) bahwa teknologi yang tidak selalu menghadirkan kebaikan, mengimplikasikan betapa pentingnya peran ilmu-ilmu sosial dan humaniora dalam pengembangan teknologi di Indonesia di masa depan. Ada beberapa alasan sangat mendasar mengapa ilmu-ilmu sosial humaniora dan perkembangan teknologi di Indonesia di masa mendatang merupakan sebuah imperative: 1) cepat atau lambat masyarakat Indonesia akan mengalami transformasi sosial menuju sebuah sistem teknologi atau teknokrasi sebagai konsekuensi dari mengalirnya teknologi dari negara-negara industri maju; 2) Erat kaitannya dampak perkembangan teknologi terhadap umat manusia/individu, masayarakat, dan lingkungan.

Belajar dari sejarah panjang pengalaman negara-negara maju, kita mengetahui bahwa perkembangan teknologi dan ilmu pengetahuan yang melahirkannya tidak selalu menghasilkan "kemaslahatan" akan tetapi sering kali juga "kemudharatan". Lebih dari itu, di dalam era teknokrasi di bawah tekanan ekspansi globalisasi gelombang ketiga, ketika rasionalitas manusia dihegemoni dan didominasi oleh "rasionalitas teknik" (meminjam ungkapan kaum post- 
modernis), perkembangan teknologi seringkali memiliki kecenderungan lebih banyak menghasilkan kemudharatan daripada kecenderungannya menghasilkan kemaslahatan bagi kehidupan manusia, masyarakat, dan lingkungan.

Ilmu-ilmu sosial dan humaniora dalam pengembangan teknologi, yang sesungguhnya merupakan remifikasi dari alasan kedua, bertalian sangat erat dengan pentingnya pemahaman tentang "kaitan-kaitan ke depan" (forward linkages) dan "kaitan-kaitan ke belakang" (backward linkages) yang menghubungkan perkembangan teknologi di satu sisi dengan sistem sosial, ekonomi, dan politik yang menjadi konteks dan konsekuensi dari penciptaan dan pemanfaatannya di sisi yang lain. Alasan ini sungguh sangat penting oleh karena dengan demikian peluang lebih besar bagi terjadinya komunikasi dan dialog antara para ahli "ilmu -ilmu sains-keteknikan" dan "ilmu-ilmu sosial dan humaniora akan menjadi semakin terbuka, sehingga perkembangan teknologi yang mereka dihasilkan tidak hanya berupa "teknologiteknologi keras" (hard technologies) yang tidak peduli terhadap potensi toksik yang dapat mereka timbulkan, melainkan juga "teknologi-teknologi lunak" (soft technologies) yang sangat peduli akan kemungkinan terjadinya dampak toksik yang mereka produksi dan reproduksi terhadap kehidupan umat manusia, masyarakat, dan lingkungan (Nasikun, 2004:1). Dengan demikian sangat penting sumbangan ilmu-ilmu sosial dan humaniora didalam mewujudkan peran liberasi dan humanisasi teknologi bagi kehidupan umat manusia dalam konteks globalisasi ideologi industrialisasi saat ini yang semakin problematik.

Kembali pada persoalannya, bagaimana jika senjakala humaniora diberlakukan juga di Indonesia. Apabila menafsirkan dari perkembangan yang mungkin timbul kemudian, penulis melihat kondisi masyarakat Indonesia yang belum ajeg dengan nilai-nilai filosofi, sejarah, dan budaya, dan yang ada justru 'krisis mental kemanusiaan' dengan berbagai macam kasus, seperti korupsi, perkelahian, konsumerisme, ketidakadilan, ketertindasan, penyimpangan, dsb. Kondisi ini menunjukkan, apabila ilmu sosial-humaniora diabaikan atau sama sekali dihapus/ditutup, tidak dapat dibayangkan bagaimana bangsa ini ke depan. Generasi yang punya sense of humanities sepertinya akan hilang karena tergerus oleh arus globalisasi yang membawa pada egoism, hedonism, keserakahan yang jauh dari nilai-nilai kemanusiaan. Untuk itu, perkembangan modernitas dalam arus globalisasi yang terjadi di Indonesia, kebutuhan sosial-humaniora tetap ada dalam penyeimbangan. 
Upaya untuk mengatasi persoalan krisis kemanusiaan, kita dapat belajar dari perjalanan perkembangan ilmu humaniora itu sendiri. Dalam pendidikan humaniora dapat ditampilkan kehadiran sosok-sosok humanis dalam sejarah peradaban yang menghendaki kebaikan bagi umat manusia. Berdasarkan pernyataan ini, ada satu topik berita yang dimuat di harian Kompas dengan judul "Kebangkitan Nasional: Elite, Belajarlah ke Soekarno-Hatta" (Gonggong, 2015). Gonggong menyatakan banyak sebenarnya tokoh-tokoh pergerakan yang berperan dalam kebangkitan nasional (khususnya Soekarno-Hatta) yang "Tanpa kejujuran terhadap diri sendiri”, Soekarno-Hatta tidak mungkin mampu berjuang. Karena jujur dengan diri sendiri dan memegang kuat komitmen kepada rakyat, mereka bisa menolak iming-iming dan segala macam tawaran dari Pemerintah Belanda. Di sini mereka memperlihatkan sikap berkorban, rela ditangkap, diasingkan, dan hidup terlunta-lunta demi bangsa. Keutamaan karakter dua pemimpin seperti inilah yang sekarang sangat jarang ditemukan. Gonggong menyebutnya "alih-alih berkorban untuk bangsa, pemimpin sekarang justru mengutamakan keuntungan pribadi, keluarga, atau partainya" (Pikiran Rakyat, Mei 2015).

Pendapat Gonggong tersebut cukup beralasan karena kita bisa lihat bagaimana, misalnya pertengkaran politik sekarang sudah sangat memalukan. Jika bercermin dari kebangkitan nasional, mereka sibuk berjuang membela rakyat dan bangsa, sekarang para pemimpin justru bertengkar demi kepentingan sendiri-sendiri atau partainya. Persoalan krisis moral kemanusian bangsa ini seolah terus bertambah. Menurut Menteri Pemberdayaan Aparatur Negara (Pikiran Rakyat, 2015) seharusnya pengabdian aparatur negara ditujukan untuk kepentingan bangsa, Negara, dan masyarakat. Untuk itu diharapkan aparatur kembali memahami dan mengamalkan nilai-nilai patriotisme dan nasionalisme.

Untuk itu, dalam perkembangan kehidupan masyarakat di era globalisasi yang semakin meluas, dengan segala kelebihan dan dampaknya, sebenarnya sangat diperlukan sinerjitas ilmu humaniora dengan ilmu-ilmu lainnya (sains-keteknikan) yang diharapkan dapat menjadi kontrol untuk mengarahkan berbagai aspek kehidupan manusia agar menjadi lebih manusiawi. Humaniora membimbing manusia menjadi reflektif dalam menyelami nilai-nilai kemanusiaanya. Posisi humaniora perlu benar-benar diperhatikan urgensinya dengan mengembangkan orientasi keilmuan di universitas secara lintas disiplin. 


\section{Simpulan}

Ada dua hal penting yang perlu dicatat di sini, bahwa pertama kehidupan masyarakat manusia tidak lepas dari perkembangan arus globalisasi yang membawa modernitas pada kemajuan teknologi. Untuk menghadapi arus tersebut manusia perlu mempersiapkan diri dengan keterampilan dan kemahiran teknis agar dapat menguasai teknologi. Kedua pada sisi lainnya, manusia juga perlu dibekali dengan kebutuhan untuk hidup dalam masyarakat demokratis. Hal ini tidak lepas dari dasar-dasar fundamental yang perlu diperjuangkan manusia, antara lain pada dasarnya manusia memerlukan bantuan orang lain, manusia memerlukan komunikasi dengan manusia lainnya, manusia memerlukan hubungan kasih sayang (cinta kasih) dengan sesama, setiap orang memerlukan suatu konsep tentang jati diri, manusia perlu untuk mengembangkan seluruh potensinya, setiap manusia memerlukan kemerdekaan, dan setiap manusia patut mendapat kesempatan untuk berkreasi. Dengan demikian, antara ilmu sains-keteknikan dan sosial-humaniora menjadi ilmu yang dapat saling mengisi, memberikan manfaat bagi masyarakat, dan tidak mungkin untuk menggantikan atau kedudukan satu lebih superioritas dari ilmu lainnya. Untuk itu keseimbangan bidang ilmu (sains-keteknikan dan sosial-humaniora) yang perlu diperhatikan, bukan pada penutupan atau pengkultusan pada satu disiplin ilmu saja. Dampak lain terhadap perkembangan ilmu dan filsafat ilmu, sosial-humaniora akan tetap eksis dalam “dominasi” ilmu-ilmu sains-keteknikan sebagaimana terjadi pada abad ke-21 ini.

\section{DAFTAR PUSTAKA}

Alhumami, Amich. 2016. "Bidang Ilmu di Perguruan Tinggi”. Jakarta: Kompas

Gardner, R. (2000). Social Theory: Continuity and Confrontation, A Readers, New South Wales: Broadview Press. Rozelle.

Gonggong, Anhar. 2015. "Kebangkitan Nasional: Elite, Belajarlah ke Soekarno-Hatta". Bandung: Pikiran Rakyat

Grumet, M.R. 1985. "Humanities Education" dalam The International Encyclopedia of Education. Research and Studies. Jilid 4. Oxford: Pergamon Press

Eagleton, T. 2010. "The Death of Universities". https://www.theguardian.com/ commentisfree/2010/dec/17/death-universities-malaise-tuition-fees

Kartodirdjo, Sartono. 1992. Pendekatan Ilmu Sosial Dalam Metodologi Sejarah. Jakarta; PT Gramedia Pustaka Utama

457 | Seminar Nasional Sejarah ke 4 Jurusan Pendidikan Sejarah Universitas Negeri Padang 
Latif, Y. (Editor). 1994. Teknologi, Emansipasi dan Transedensi. Bandung: Mizan

Nasikun. 2004. "Peran Penelitian Ilmu-Ilmu Sosial dan Humaniora Bagi Liberasi dan Humanisasi Teknologi’. Seminar Mingguan Fakultas Ilmu Sosial dan Ilmu Politik, Universitas Airlangga, Surabaya, tanggal 27 Oktober 2004.

Ning, Wang. 2016. "Globalization, Humanities and Social Sciences: An Introduction and Commentary”. European Review, Vol. 24. Mo. 2, 177-185

Rahman, Fadly. 2016. "Senjakala Humaniora”. Jakarta: Kompas

Sjamsuddin, Helius. 2012. Metodologi Sejarah. Yogyakarta: Ombak

Wiriaatmadja, Rochiati. 2015. Filsafat Ilmu Relevansinya dengan Pendidikan IPS. Bandung: Rizqi 